\title{
Knowledge Gaps, Belief Gaps, Ideology, and Culture Wars
}

\author{
Cecilie Gaziano \\ Research Solutions, Inc., Minneapolis, USA \\ Email: cgaziano@prodigy.net
}

Received July $13^{\text {th }}, 2013$; revised August $12^{\text {th }}, 2013$; accepted August $22^{\text {nd }}, 2013$

\begin{abstract}
Copyright (C) 2013 Cecilie Gaziano. This is an open access article distributed under the Creative Commons Attribution License, which permits unrestricted use, distribution, and reproduction in any medium, provided the original work is properly cited.
\end{abstract}

\begin{abstract}
Ideological and partisan fissures increasingly divide the United States into opposing factions. This article discusses a theoretical framework for research on knowledge and belief gaps in order to better understand increasing gulfs between conservatives and liberals. The perspective develops from "knowledge gap" research (Tichenor, Donohue, \& Olien, 1970), a "belief-knowledge gap" hypothesis (Gaziano \& Gaziano, 1999, 2009), and Hindman's "belief gap" research $(2009,2012)$. Hindman distinguished between knowledge as empirically observed by scientists and beliefs or views accepted without an empirical foundation, frequently based on religious faith. He, like Gaziano and Gaziano, considered knowledge to be socially constructed. The Gaziano and Gaziano perspective treats knowledge as a form of belief and ideology as a multifaceted concept, maintaining that social and political groups differ in personality, values, moral foundations, attitudes, reasoning styles, conceptions of power relations, and even neurological and genetic make-up. This helps to explain why conservatives and liberals can appear to be two cultures. Their level of analysis is collective, rather than individual, a main tenet is that beliefs are knowledge, and the unit of analysis is "belief-knowledge" differences between ideological segments of social subsystems. This perspective advocates approaching ideology from a viewpoint of understanding differences. One can begin to frame solutions to ideological conflicts by accepting the other side as valid, by trying to understand the differences, and by appealing to the other cultural groups' values, conceptual systems, mores, and social life. An important question is how the interests and beliefs of conservatives and liberals, as well as moderates, can be addressed to improve social and political system functioning instead of driving them further apart. The article proposes hypotheses and research questions for future research.
\end{abstract}

Keywords: Knowledge Gap; Belief Gap; Ideology; Polarization; Political Theory; Culture Wars

\section{Introduction}

Both political elites and the public have become more polarized along ideological and partisan lines in the United States since the 1970s (Abramowitz \& Saunders, 2005; Layman, Carsey, \& Horowitz, 2006; McCarty, Poole, \& Rosenthal, 2006; Shapiro \& Bloch-Elkon, 2008; Treier and Hillygus, 2009). Some see this phenomenon as developing from a sorting process whereby conservatives increasingly identify as Republicans and liberals increasingly identify as Democrats (Levendusky, 2009). Others view this as a process deriving from social distance theory whereby "both Republicans and Democrats increasingly dislike, even loathe, their opponents" (Iyengar, Sood, \& Lelkes, 2012: p. 405).

Regardless of which underlying forces may be at work, polarization figures prominently in debates about controversial scientific issues such as global warming and climate change (Hindman, 2009; Ladwig, 2010; McCright \& Dunlap, 2011), stem cell research (Ho, Brossard, \& Scheufele, 2008), sexuality (Burack, 2008; Hindman \& Yan, 2012; Smith, 2001), and evolution (Ladwig, 2010). Ideological and partisan divisions extend to a wide range of issues beyond scientific matters, such as whether or not Iraq had weapons of mass destruction, numbers of casualties in the Iraq war, national economic conditions, economic inequality, welfare issues, healthcare reform, and
Social Security (Abramowitz \& Saunders, 2005; Bartels, 2002; Blake \& Culley, 2011; Daves, White, \& Everett, 2011; Hindman, 2012; Shapiro \& Bloch-Elkon, 2008).

Some scholars perceive these clashes over social, moral, or cultural issues to be the eruptions of two different cultures into "culture wars" (Gramsci, 1916-1935, 2000); Hunter, 1992; Thomson, 2010; Zimmerman, 2002). Many view this schism with apprehension, and reasons for these developments are the subject of much research. While conflict can be an important element in the process of public opinion formation, irresolvable conflict harms the democratic process.

The objective of this article is to discuss a theoretical framework for research on knowledge and belief disparities in order to better understand increasing gulfs between conservatives and liberals and between Republicans and Democrats. The framework develops from "knowledge gap" research (Tichenor, Donohue, \& Olien, 1970), a "belief-knowledge gap" hypothesis (Gaziano \& Gaziano, 1999, 2009), and Hindman's "belief gap" research $(2009,2012$; Hindman \& Yan, 2012). Ideology is defined as a philosophy or body of ideas that forms the basis of a political, economic, social, or other system, reflects its needs and interests, and provides blueprints for action ${ }^{1}$. Main ele-

\footnotetext{
${ }^{1}$ Retrieved from: http://www.thefreedictionary.com/ideology.
} 
ments of American conservatism include a "political philosophy or attitude emphasizing respect for traditional institutions, distrust of government activism, and opposition to sudden change in the established order",2. Political liberalism in the US supports reform, openness to innovative ideas, tolerance, broadmindedness, and willingness to question tradition ${ }^{3}$.

\section{Building on the Knowledge Gap Hypothesis}

The theoretical framework developed first from work on the knowledge gap hypothesis by Tichenor et al. (1970: pp. 159-160), who postulated that: "As the infusion of mass media information into a social system increases, segments of the population with higher socioeconomic status [SES] tend to acquire this information at a faster rate than the lower status segments, so that the gap in knowledge between these segments tends to increase rather than decrease". Much research supports the hypothesis, although many scholars have focused on conditions under which the gap increases or decreases (Gaziano, 1997; Gaziano \& Gaziano, 2009; Hwang \& Jeong, 2009; Viswanath \& Finnegan, 1996). The Minnesota team emphasized the importance of studying information control (Donohue, Tichenor, \& Olien, 1973; Tichenor, Donohue, \& Olien, 1973). Their questions were: Who will assert control over the definition, creation, and dissemination or suppression of knowledge within what parts of the social system? Hindman (2009) and Gaziano and Gaziano (1999) also ask these questions but differ in definition of beliefs and knowledge.

\section{Beliefs versus Knowledge}

Hindman $(2009,2012)$ distinguished between knowledge as value-free, cumulative, empirically observed by scientists and beliefs or views accepted without an empirical foundation, frequently based on religious faith. His 2009 article referred to "politically disputed beliefs" socially constructed, which social actors can bend to their own purposes. His 2012 article stated, "Beliefs are claims about reality that are not based on evidence, but are instead based on value systems, loyalties, reference groups, social institutions, elite opinions, and ideological predispositions" (pp. 589-590). Hindman (2009) saw beliefs as time-saving thought processes involving little, if any, critical evaluation. Interest groups and political elites seek the power "to define what counts as knowledge, how problems are defined, and which problems are addressed" (p. 792).

He proposed that: "Political ideology is a better predictor of the distribution of politically disputed beliefs than is education" and, second, that: "As the infusion of mass media information into the system increases over time, the relationship between political ideology and politically disputed beliefs tends to strengthen" (p. 794).

\section{Beliefs Are Knowledge}

It is not always easy, however, to distinguish clearly between knowledge and belief. For example, McCright \& Dunlap (2011) talked about beliefs consistent or inconsistent with the scientific

\footnotetext{
${ }^{2}$ Retrieved from American Heritage Dictionary:

http://ahdictionary.com/word/search.html?q=conservative.

${ }^{3}$ Retrieved from the American Heritage Dictionary:

http://ahdictionary.com/word/search.html?q=liberal.
}

consensus about climate change ${ }^{4}$. Kuklinski, Quirk, Jerit, Schweider, and Rich (2000, 792-793) observed: "To be informed requires, first, that people have factual beliefs and, second, that the beliefs be accurate. If people do not hold factual beliefs at all, they are merely uninformed. They are, with respect to the particular matter, in the dark. But if they firmly hold beliefs that happen to be wrong, they are misinformed - not just in the dark, but wrongheaded". Gaines, Kuklinski, Quirk, Peyton, and Verkuilen (2007) point out that people may possess facts about an issue, but:

Partisan-motivated interpretations can intercede between even accurate factual beliefs and policy opinions. Indeed, in what may be a central paradox of mass politics, those who acquire the most information about a policy and its consequences are also the most likely to rationalize their existing opinions. They have the motivation and ability to use interpretations for that purpose. Facts might play a smaller part in political life than generations of scholars have maintained.

People's perceptions of understanding complicated issues about which they actually know little can contribute to extreme political attitudes, according to Fernbach, Rogers, Fox, and Sloman (2013).

Gaziano and Gaziano (1999) viewed all knowledge, including scientifically supported knowledge, as a form of belief and termed their perspective the "belief-knowledge gap". A "belief" is an opinion, conviction, confidence in the truth or existence of something not immediately susceptible to rigorous proof, faith, or trust, a principle or idea accepted as true ${ }^{5}$. Scientific knowledge is a form of belief, based on systematic examination of evidence, according to widely accepted scientific principles such as being able to prove a theory false but not to prove it true - only to support it. Other types of belief, such as religious belief, may be based on acceptance of information that has not been subjected to systematic observation of physical evidence. Belief could be based on study of religious texts such as the Bible, in a methodical manner, for example, and be perceived as real.

See Evans and Evans (2008) for more on the social construction of both religious and scientific knowledge (p. 97):

The earliest canonical texts in what became the sociology of scientific knowledge (SSK), published in the late 1970s and early 1980 s, made the case that scientific knowledge is socially constructed, like any other knowledge... Such studies examine religion and science not as feuding symbol systems, but rather as social conflicts between institutions struggling for power, with the content of the symbol systems definitively bracketed.

When scientists prevail in conflicts between religion and science it is not because of the perception of scientific ideas as

\footnotetext{
${ }^{4}$ The seminal knowledge gap article by Tichenor et al. (1970) included, among a number of knowledge indicators, two belief measures: belief that "man would reach the moon" within a certain number of years and belief that "cigarettes cause lung cancer". Hwang and Jeong (2009) included beliefs in their conceptualizations of four types of knowledge, the others being factual, awareness, and combinations of these. They characterized "belief knowledge" as counting the arguments that respondents supply about a topic that is, collecting open-ended responses, as opposed to closed-ended responses. These definitions lack conceptual clarity, however.

${ }^{5}$ Collins English Dictionary, Complete \& Unabridged 10th Edition. Retrieved from http://dictionary.reference.com/browse/belief.
} 
"truth" but because certain institutions were regarded as more credible (Evans \& Evans, 2008).

Social construction refers to the meaning given to concepts or practices as a result of individuals' and groups' patterns of interaction and development of institutions, including beliefs about the reality of these things, rather than intrinsic qualities that exist outside of social contexts. Liberals and conservatives may receive the same information and agree on the facts, for example, the numbers of troop casualties in the Iraq War, but they may differ on what the facts mean (Gaines et al., 2007). One group can perceive the number of casualties as low, while the other regards the figure as high. Receiving additional empirically-based information does not ensure that people will change their beliefs (Iyengar \& Hahn, 2009; McCright \& Dunlap, 2011; Nyhan \& Reiffler, 2010). Misinformation, not supported by evidence, can be involved as well, especially that disseminated by partisans or elite opponents of a policy such as health care reform (Nyhan, 2010). Conservatives and liberals can perceive each other's "partisan-motivated interpretations" as "misperceptions", setting the stage for deeper rifts between them (Gaines et al., 2007).

The belief-knowledge disparity framework includes the following assumptions: Beliefs are knowledge. Different groups value the acquisition of knowledge differently or evaluate various kinds of knowledge differently. Causes of knowledge inequities are located primarily in processes of social definition-different groups possess different social definitions. The social system of stratification can play a role in establishing knowledge differentials and creating differences among groups in their construction of knowledge and definitions.

Groups vary in their ability to control knowledge, and "social construction of knowledge is often an important means of social control in itself. Control of knowledge that is functional for one group can be dysfunctional for another" (p. 131). Conflict resolution is more complicated when groups clash on definitions of issues. It is important to know how groups vary in values, beliefs, personality, norms, and definitions of what counts as knowledge when searching for solutions to social conflicts. Although conflict frequently tends to distribute knowledge more equally in a community or a society (Donohue, Tichenor, \& Olien, 1975), conflict appears to increase the development of belief gaps (Gaines et al., 2007; Gauchat, 2012; Hindman, 2009, 2012; Kuklinski et al., 2000).

The Gaziano and Gaziano (1999) framework recasts the original knowledge gap hypothesis as follows (p. 130): “As the infusion of mass media information into society increases, certain groups will tend to acquire this information at a faster rate than other groups, so that the gap in knowledge between these groups tends to increase because of differences in their social construction of knowledge - that is, their cultures". This perspective agrees with Hindman $(2009,2012)$ that partisans and elites seek to be in command of the definitions of issues and the outcome of debate about them with an eye to their own benefit.

\section{Differences between Conservatives and Liberals}

Before proceeding further, some important findings about ways in which liberals and conservatives diverge should be taken into account.

\section{Attitudes toward Change and Equality}

According to some theorists, conservatism has two main components, resistance to change and support of inequality, because of needs to reduce uncertainty and threat; liberalism is the tendency to support change and oppose inequality (Jost, Glaser, Kruglanski, \& Sulloway, 2003; Koleva \& Rip, 2009). Uncertainty and threat management had independent effects on self-reported political conservatism, even when ideological extremity was taken into account (Jost, Napier, Thorisdottir, Gosling, Palfai, \& Ostafin, 2007). For example, individual variations in death anxiety were significantly related to conservatism but not to ideological extremity.

A meta-analysis of data from 12 countries considered how well various psychological variables such as dogmatism are related to political constructs such as Right Wing Authoritarianism, the General Conservatism Scale, and the C-Scale (Jost et al., 2003), all of which are relevant to attitudes toward change and equality. The authors presented an "integrative model of political conservatism as motivated conservatism" showing uncertainty and fear or threat as environmental stimuli acting on three categories of social-cognitive motives, all of which act on political conservatism, leading to resistance to change and endorsement of inequality. The social-cognitive motives included epistemic motives (intolerance of ambiguity, uncertainty avoidance, need for order), existential motives (self-esteem, loss prevention, terror management), and ideological motives (rationalization of self-interest, group-based dominance, system justification). Motives and outcomes may vary by SES. For example, low status groups may be more inclined to respond to fear, threat, or insecurity by becoming more conservative and attracted to right-wing beliefs, in contrast to higher status groups who may react by adopting more conservative philosophies out of self-interest or social dominance motives.

Another meta-analysis of 19 Eastern and Western European nations used more generalizable population data from the European Social Survey (Thorisdottir, Jost, Liviatan, \& Shrout, 2007), in contrast to the earlier study, which relied considerably on university student samples. Their expectation of one form of resistance to change - traditionalism - and a form of need for order-rule-following - as predictors of right-wing conservatism held in both Eastern and Western Europe. Acceptance of inequality, an indicator of conservatism, was sustained as a predictor only in the West, however. Openness to experience, a frequent gauge of liberalism, held in the West but was connected to right-wing orientation in the East. The need for security, associated with right-wing orientation in research mainly in the United States, was affirmed for Western Europe but was related to left-wing orientation in Eastern Europe. One reason for differences was the history of repressive left-wing rule in Eastern Europe. The structures of political and economic systems, therefore, play mediating roles in relationships with leftright orientations. The investigators also concluded that cultural conservatism and economic conservatism are somewhat different concepts ${ }^{6}$.

\section{Moral Foundations Differ for Liberals and Conservatives}

Conservatives and liberals draw on different moral founda-

\footnotetext{
${ }^{6}$ Although only four Eastern European nations were represented (Hungary, Poland, the Czech Republic, and Slovenia), with more rapid economic and democratic expansion than some other Eastern European countries not included, the authors argued that the Eastern European data were of high quality, consistent, and generalizable.
} 
tions, a chief reason why they have difficulty in understanding each other, according to Haidt and Graham (2007), who identify five psychological foundations of morality: harm/care, fairness/reciprocity, ingroup/loyalty, authority/respect, and purity/sanctity. They posit that liberals focus primarily on the first two of these, but that conservatives draw upon all five. The latter three principles have to do with loyalty to one's group (kin, country), respect for authority, and self-restraint from "carnal" and "disgusting" behaviors (see, e.g., Inbar, Pizarro, \& Bloom, 2009).

\section{Ideological Differences on the "Big Five" Personality Characteristics}

Some studies of ideology measure the "Big Five" personality factors: agreeableness, conscientiousness, extraversion, neuroticism, and openness, at least some of which are associated with ideology. For example, Gerber, Huber, Raso, and Ha (2009, p. 24), stated:

The strong linkage between the Big Five personality dimensions and political attitudes suggests that conservatives and liberals appear to be different sorts of people, not just people who happen to hold different political views. These findings imply that personality may be an important and neglected precursor to basic political orientations and that personality may shape (directly or indirectly) evaluations of contemporary political officials and voting decisions.

Agreeableness was associated with liberalism, and conscientiousness and emotional stability were linked to conservatism in their large study. In one small study, conservatism tended to be negatively correlated with openness and neuroticism and positively correlated with conscientiousness, extraversion, and agreeableness (Thornhill \& Fincher, 2007). Liberalism, in contrast, was negatively correlated with the latter three variables and positively associated with neuroticism and openness. All correlations were modest.

A small study from 1969 to 1971 of children born in the late 1960s provides data on the influence of personality in childhood and ideology (Block \& Block, 2006). The youngsters lived in Berkeley and Oakland, CA, varied in socioeconomic levels, and attended two different nursery schools. Usable data were obtained from 95 of the original 128 children. Personality evaluations were conducted while they were in nursery school as part of the Block and Block Longitudinal Study of Cognitive and Ego Development at the University of California at Berkeley. These personality evaluations predicted ideological attitudes years later when they were 23 years of age. The 49 females and 46 males completed self-reports during several weeks on seven measures: a five-point liberal-conservative selfrating scale, positions on issues such as abortion rights, a political rights (tolerance) scale, the Kerlinger Liberalism and Conservatism scales, personal political activism, and perceptions of the positions of the two major political parties. The males and females were analyzed separately. The first six measures were convergent and used to construct a composite "LIB/CON" score that was skewed toward liberalism, although those scoring as conservative were relatively more homogeneous.

The more conservative young adults had been described in nursery school as uncomfortable with uncertainty, indecisive, fearful, rigid, more typed in sex roles, more likely to feel offended, and more moralistic, among other attributes. Gender differences were more evident, with females more often described as quiet, neat, and compliant, and males more often characterized as offering unsolicited advice. The more liberal young adults had been seen as more self-reliant, resilient, more likely to connect with others, relatively more non-conforming, and autonomous. As children, the girls had been evaluated as talkative, more dominating, aggressive, and judgmental of their peers. The boys had been described as introspective, wider ranging in interests, and more likely to see simple concepts in more complex terms.

\section{Attachment Style and Political Orientation}

In contrast to the findings of Block and Block (2006), having experienced more childhood stresses and having a sense of less secure attachment to one's primary caregiver or caring others may predispose people to be more liberal, while more secure attachments and lower childhood stress may predispose them to be more conservative, according to Thornhill and Fincher (2007). Briefly, attachment theory originally concerned how well the primary caregiver was able to respond to the emotional needs of the child in the early years of life (Bowlby, 1969). The literature distinguishes secure parent-child attachment and four types of insecure attachments (Crittenden \& Ainsworth, 1989; Main \& Solomon, 1986). Studies of adult attachment tend to concern romantic relationships. Unlike Thornhill and Fincher (2007), three other studies of adult attachment and political orientation linked greater security of attachment to more liberal political orientations (Gillath \& Hart, 2009; Weber \& Federico, 2007; Weise et al., 2008), although findings were somewhat mixed (Koleva \& Rip, 2009). One criticism of these studies, all of college students, is that this youthful population segment does not mirror the general population and may not have had much experience with the type of attachment measured-romantic attachments (Koleva \& Rip, 2009). Also, the studies' operational definitions of attachment are not necessarily comparable. The work of Thornhill \& Fincher (2007), Weber and Federico (2007), and Weise et al. (2008) featured three different kinds of adult attachment scales, and Gillath and Hart (2009) simply used an "attachment security prime" with three conditions measured by one item - thinking of a secure attachment figure, a close non-attachment figure, or an acquaintance.

\section{Ideology Based on a Conception of Parent-Child Power Relations}

People may tend to understand ideology in terms of power relations and ultimately, government-citizen relations, according to the earliest example to which they are exposed-the parent-child relationship (Barker \& Tinnick, 2006; Feldman \& Stenner, 1997; Lakoff, 2002). In part, the social construction of ideology stems from perceptions of parent-child relations as either nurturance (related to liberalism) or discipline (related to conservatism), and it conditions their views of appropriate government citizen relations, according to Lakoff's theory, tested by Barker \& Tinnick (2006). Those who lean toward the nurturant model are more likely to stress egalitarian and compassionate values; those inclined toward the disciplinarian model tend to emphasize political individualism and traditionalism (Barker \& Tinnick, 2006; Lakoff, 2002). 
Lakoff's (2002) nurturant model stresses parent-child discussion with explanations for rules and with give and take, allowing for conflict and disagreement. This model values empathy, social responsibility, and cooperation (Barker \& Tinnick, 2006). Lakoff's "strict father", or disciplinarian, model stresses strict adherence to authority, punishment for infractions of rules, and competition, in order to protect children from a dangerous and difficult world. This model emphasizes personal responsibility, self-discipline, and strong morals. Other models are possible, and many families fall in between these opposites (e.g., see Maccoby \& Martin, 1983).

Barker and Tinnick (2006) tested Lakoff's theory with data from the 2000 American National Election Study (ANES), which allowed construction of an index of items concerning the qualities that children should have ${ }^{7}$. The authors also created variables measuring strength of partisanship and strength of ideology, as well as indices of value orientations, attitudes toward ten social and political issues, and predictors of vote choice and ideological constraint (directional and non-directional). Child rearing scores predicted attitudes toward a variety of issues and of conservatism or liberalism, supporting Lakoff's hypothesis.

\section{Neurological and Genetic Evidence for Ideological Dissimilarities}

Political orientation can be detected even by research on the brain, as a small experiment with 43 right-handed participants demonstrated (Amodio, Jost, Master, \& Yee, 2007). Participants recorded their political attitudes on a scale from extremely liberal $(-5)$ to extremely conservative $(+5)$, and they also responded to a series of tasks calling for a "Go" response as a habitual reaction. Some trials, however, required a "NoGo" response, a stimulus conflict that tends to produce enhanced anterior cingulated cortex activity, which can be measured by functional magnetic resonance imaging. Being more liberal was highly correlated with several neurocognitive patterns related to adjustment to stimulus changes and response accuracy. These results were considered to be consistent with previous research showing liberals to be more adaptable to information complexity, ambiguity and novelty, and conservatives to be more responsive to more structured, orderly, and predictable situations.

Genetics partially accounts for ideology, according to Alford, Funk, and Hibbing (2005). It is not that specific attitudes are inherited but that genotypes (genetic makeup) of people influence predispositions to attitudes and behaviors, depending on environmental factors. Estimates of influences of nature and nurture come from two large studies of twins in the United States and in Australia. The twins studies are valuable because two kinds of twins are involved in comparisons. The first is monozygotic (MZ) twins, frequently called "identical", that form from a single egg fertilized by a single sperm. The technical name for these twins is "diamnionic monochorionic" (a

\footnotetext{
${ }^{7}$ The question wording was: "Although there are a number of qualities that people feel children should have, every person thinks that some are more important than others. I am going to read you pairs of desirable qualities. Please tell me which one you think is more important for children to have: (1) Independence or respect for elders? (2) Curiosity or good manners? (3) Being considerate or well behaved?" The disciplinarian responses are boldfaced; these were coded as " 0 ". The other responses, nurturant model, were coded as " 1 ". Responses were summed to produce a scale ranging from 0 to 3 .
}

small subset is "monoamnionic monochorionic"). The second type of twins is "diamnionic dichorionic," or DZ twins, commonly known as "fraternal", which develop from separate eggs fertilized by separate sperms, and they share $50 \%$ of their genetic makeup, in contrast to $\mathrm{MZ}$ twins, which share $100 \%$ of genetic makeup.

Modeling procedures have been developed to partition the contributions of heredity, shared environment, and unshared environment in order to compare the correlations of $\mathrm{MZ}$ and DZ twins on a wide range of variables, controlling for parental traits and assortative mating of parents. Twins studies typically are not conducted by political scientists, and the psychologists who conduct twins research tend to think of political attitudes as psychological traits, so political attitude measurement has been less than ideal. A number of twins studies include measures of conservatism with a Wilson-Patterson (W-P) Attitude Inventory, however. Alford and his colleagues (2005) gained access to W-P data on thousands of American twin pairs, supplemented by correlational analysis of published Australian twin study results. Correlations were analyzed separately for male/male and female/female twin pairs, excluding female/ male DZ twin pairs.

In the Virginia data heritability ranged from .18 to .41 , and all differences between $\mathrm{MZ}$ and DZ correlations were significant at .01. The mean estimate of the $28 \mathrm{~W}-\mathrm{P}$ items was .32 for heritability, the mean estimate of shared environmental influence was .16, and the mean for unshared environment was .53. A continuous variable was created further from the responses, and the estimates of this index of ideological attitudes was .43 for heritability, .22 for shared environment, and .35 for unshared environment. In comparison, heritability of political party affiliation was a mere .14; the mean for shared environment was .41 and for unshared environment, .45. On the other hand, means of affect toward Republicans and Democrats were: heritability, .31; shared environment, .17; and unshared environment, .52. Genetics played an intriguing role in ideological and party attitudes but scarcely any role in political party affiliation. In general, the Australian data were similar when attitudes on specific issues, such as censorship, the death penalty, and segregation, were examined.

Alford and his colleagues (2005) explained further that perhaps the genetic components underlying these results are orientations or phenotypes that "run to the very orientation of people to society, leadership, knowledge, group life, and the human condition" (p. 164).

\section{Differences in Social Power on a Collective Level}

Hindman (2009) found that ideology was a better predictor than education of beliefs that global warming has been occurring but that both education and ideology predicted beliefs that human activity was responsible for global warming (during a period from June 2006 to April 2008). A hypothesized belief gap regarding global warming between conservatives and liberals was weakly supported over time; however, it was not supported over time concerning the role of human activity. In other research party identification, however, bested education in predicting beliefs about the value of health care reform during September 2009 and January 2010 (Hindman, 2012). In addition, partisanship was more powerful than education in predicting knowledge about the contents of the health care reform bill before Congress, and the relation between partisanship and 
knowledge increased during this period. Younger people, females, nonwhites, and those with lower incomes perceived the greatest value in health care reform. Hindman (2012) pointed out that these groups stood to benefit the most from health care reform. Those with highest interest in the issue, on the other hand, tended not to see the value of the bill personally or nationally. He thought the divisive tone of media coverage surrounding the proposal was partly the reason. Although education was not a predictor of knowledge over time, income, another indicator of socioeconomic status, was.

The relation of income to a range of dependent variables may vary according to the positions of ideologues and partisans on issues. Another study used 2008 ANES data to compare more and less educated conservatives, moderates, and liberals (Gaziano, 2013). Also studied were other demographics, religiosity, child rearing values, need for cognition, opinionation, orientation toward politics, and mass media. The most striking finding was that, although liberals tended to be more educated overall than conservatives, better educated conservatives had the highest household incomes and were a proportionately larger group than better educated liberals. No known knowledge gap studies have reported results on one group characterized by high education and an opposing group distinguished by a different indicator of SES, such as high incomes. It may be that when ideology-based belief-knowledge gaps occur, the most powerful underlying explanation is income, although this might vary by issue.

In many respects, the characteristics of more educated liberals contrasted dramatically with those of more educated conservatives and evoked the picture of divergent cultures. More educated liberals differed from all the other groups in a number of ways, including a greater propensity to have graduate work beyond college and to be younger, female, non-white, employed, less religious, more oriented toward thinking and complex problem solving, and being more opinionated than other groups. They varied markedly from other groups in their child rearing values but were less likely to have children because they appeared to be in earlier stages of their life-cycles than more educated conservatives were. They tended more than others to have encountered the 2008 presidential campaign in magazines and on the Internet, to not have military service, and to be willing to self-identify as homosexual or bisexual.

Conservatives outnumber liberals in the general population in the United States, and in particular, better educated conservatives are more numerous than better educated liberals. More prosperous conservatives may have more access to powerful interest groups and have advantages in accumulating social power. The growing antagonism between conservatives and liberals, Republicans and Democrats, is increasingly manifested by rising income inequality, according to McCarty et al. (2006) because the Right no longer espouses policies that work against inequality although the Left continues to advocate for policies that support equality. They argue that these forces decreased in the period from 1913 to 1957 but increased considerably in the 1970s. They examined implications for pronounced socioeconomic changes and focused especially on the part immigration occupies in these processes.

Conservatives, especially educated or church-going conservatives, are more likely than liberals to distrust science, an increasing trend according to analysis of data from the 1974 to 2010 General Social Surveys (Gauchat, 2012). Religiosity often plays a role in mistrust of science (Brossard, Scheufele, E. Kim,
\& Lewenstein, 2009; Gauchat, 2012; Gaziano, 2013; Ho et al., 2008; Ladwig, 2010). Gauchat observed, however, that more than religiosity is at work (2012, pp. 169-170): "One possible interpretation, supported by a growing number of studies, is that social factors such as race/ethnicity, income, religiosity, social capital, and political identifications are at least as important as knowledge and education in predicting trust in science (Gauchat 2008, 2010; Sturgis and Allum 2004; Yearley 2005),"8.

\section{Conceptualizing Liberals and Conservatives as Cultural Groups}

This multiplicity of characteristics helps to suggest that cultural differences are involved. Further, some key components of ideology are described below, which illustrate the argument that liberals and conservatives can be thought of as cultural groups. These elements include attitudes toward change and equality, moral foundations, personality characteristics, models of power based on parent-child relations, differentials in social power on collective levels, and neurological and genetic evidence $^{9}$. Figure 1 summarizes the relationships discussed in this paper.

The following four tables of results of logistic regressions on beliefs about sexual orientation, evolution, global warming, and causes of global warming show how predictor variables vary in strength across these issues. The poll from which these data come had several science-related questions, including sexual orientation, evolution, and global warming ${ }^{10}$. The overall tests of the models are positive, and the Hosmer and Lemeshow tests of goodness of fit between the predicted and observed probabilities in classifying the dependent variables are all low and non-significant, indicating models that fit well. The results suggest that liberals and conservatives are different cultural groups.

In Table 1 beliefs that sexual orientation can or cannot be changed were examined in a hierarchical logistic regression, in which beliefs were regressed on a first block of four key demographics, a second block including education, ideology, and political party identification, a third block containing literalness of interpretation of the Bible, frequency of attending religious

\footnotetext{
${ }^{8}$ Among the factors in such changes, according to Mooney (2005), are the rise of the "New Right" beginning when Ronald Reagan was elected president in 1980, strengthening when George W. Bush was elected president in 2000 , and burgeoning with the development of the New Right media empire. Components of the New Right - the religious right and transnational corporations - are suspicious of organized science and the intellectual establishment in colleges and universities because the religious right perceives science often to conflict with morality and religious beliefs and corporations perceive science to threaten their profitability.

${ }^{9}$ Much social science research on ideology does attempt to treat liberalism and conservatism even-handedly (e.g., Abramowitz \& Saunders, 2005; Haidt \& Graham, 2007; Thornhill \& Fincher, 2007), but some appears to take a somewhat negative tone toward conservatism and its related characteristics (Block \& Block, 2006; Jost et al., 2007), or at the very least, focuses on antecedents of conservatism while ignoring antecedents of liberalism (e.g. Jost et al., 2003). Less appears to be known about liberals' intolerance than is known about conservatives' intolerance, so more research on liberals is called for.

${ }^{10}$ Data are from the Pew Research Center for the People \& the Press and the Pew Forum on Religion \& Public Life from a survey conducted July 6-19, $2006, N=2003$. The response rate was $19.1 \%$ (AAPOR RR 4); the cooperation rate was $31.9 \%$ (AAPOR CR4). The data were weighted to adjust for age, education, nonresponse, and attrition. For the standard definitions of the American Association for Public Opinion Research (AAPOR), see: http://www.aapor.org/Home.htm.
} 


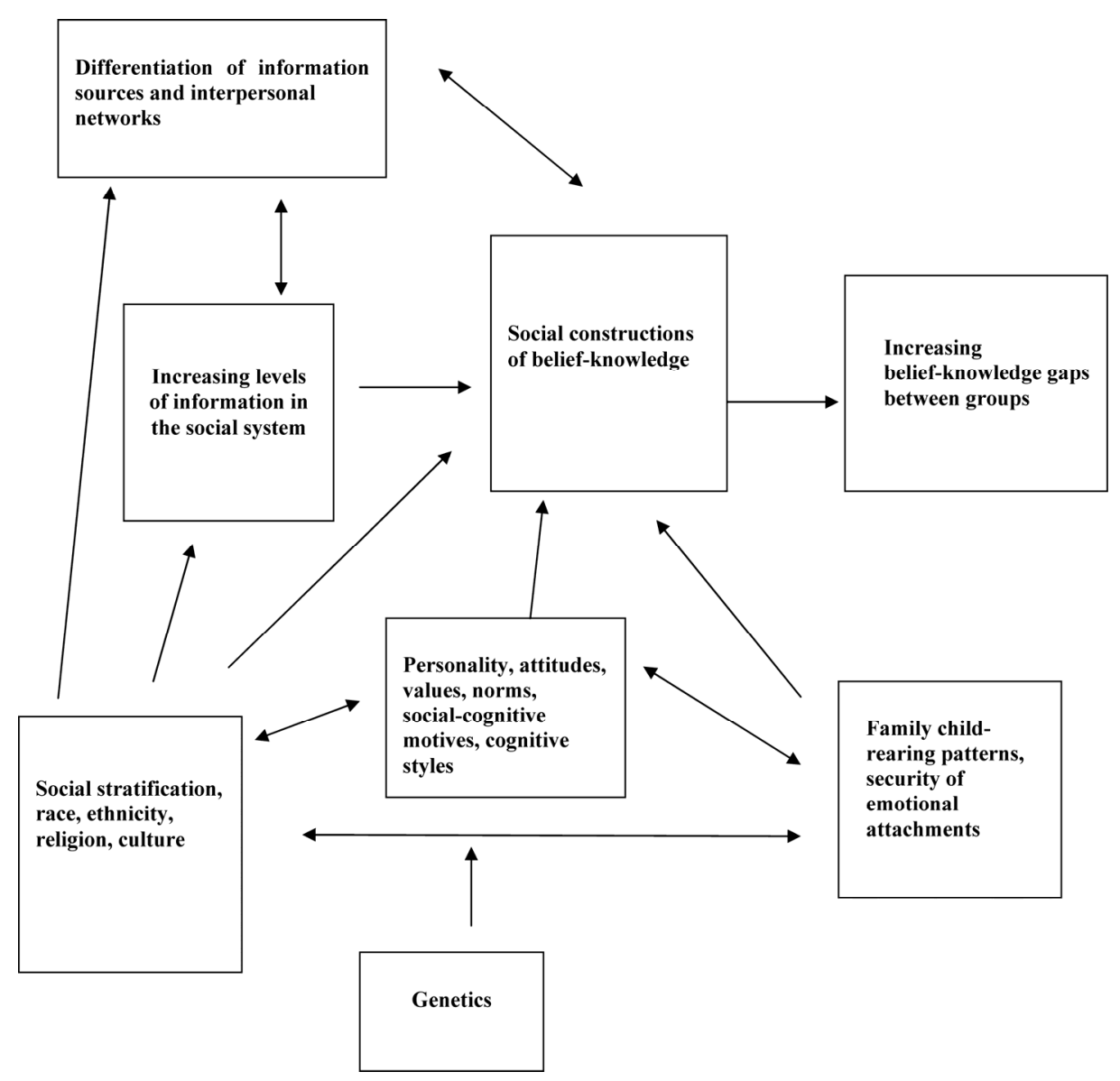

Figure 1.

Model of the belief-knowledge gap framework, including research findings about characteristics of conservatives and liberals.

services, and attitudes toward gay marriage, and then a block of interactions. Scientific evidence indicates that sexual orientation cannot be changed ${ }^{11}$. The interactions included education by ideology, income by ideology, education by religious service observance, and income by religious service attendance. The significant predictors were higher household incomes, female gender, perceiving the Bible as written by people and only partly or not at all the word of God literally, attending religious services less frequently, favoring gay marriage, and a positive interaction of education and attending religious services.

Table 2 presents a somewhat different picture with regard to belief in evolution ${ }^{12}$. Beliefs were regressed on the same blocks as in Table 1, except that the third block contained a different opinion variable, concerning teaching creationism in schools. The variables that predict belief in evolution were younger age, white race, higher education, liberal ideology, Democratic party identification, tendency to interpret the Bible less literally, less frequent attendance of religious services, negative interaction of education with ideology and also negative interaction of education with attending religious services.

The variables that predict belief in global warming, which

\footnotetext{
${ }^{11}$ Evidence that sexual orientation cannot be changed can be accessed here: http://www.apa.org/news/press/releases/2009/08/therapeutic.aspx.

${ }^{12}$ Selected references on the scientific evidence for evolution are found here: http://www.si.edu/Encyclopedia_SI/nmnh/evolve.htm.
}

the preponderance of scientific evidence supports ${ }^{13}$, shown in Table 3, were older age, female gender, being less educated, Democratic partisanship, interpreting the Bible less literally, and believing that stricter environmental laws and regulations are worth the cost.

The variables that predict belief that human activities cause global warming, the view that most scientists accept as supported by research, were higher education, liberal ideology, Democratic partisanship, believing that stricter laws and regulations are worth the financial cost, and a positive interaction of household income with frequency of attending religious services (Table 4).

Table 5 presents additional variables from a different survey ${ }^{14}$ that make a difference in attitudes concerning support for gays and lesbians being able to adopt children. The variables that predict support for homosexual couples' adoption of children were younger age, female gender, higher education, liberal ideology, Democratic partisanship, less literal interpretation of the Bible, lower attendance of religious services, lower au-

\footnotetext{
${ }^{13}$ Selected references on the scientific evidence for global warming can be found here: http://www.kings.cam.ac.uk/global-warming/index.html.

${ }^{14}$ The data are from the 2008 American National Election Study, conducted face-to-face September 2 through November 3, $2008(N=2322)$, with follow-up interviews November 5-December 30, $2008(N=2102)$. The response rate for the pre-election phase was $78.2 \%$ (RR5, as defined by AAPOR - see note 10). The post-election response rate was $57.7 \%$. The data were weighted to adjust for age, education, nonresponse, and attrition.
} 


\section{GAZIANO}

Table 1.

Logistic regression analysis of beliefs about whether or not sexual orientation can be changed.

\begin{tabular}{|c|c|c|c|c|c|c|}
\hline \multicolumn{7}{|c|}{ Do you think a gay or lesbian person's sexual orientation can be changed or cannot be changed? $\quad(0=$ "yes," $1=$ "no"a $)$} \\
\hline Predictors & $\beta$ & $S E \beta$ & Wald's $\chi^{2}$ & $d f$ & $p$ & $\operatorname{Exp}(\beta)$ (odds ratio) \\
\hline Constant & -.596 & .770 & .599 & 1 & .439 & \\
\hline Age & .008 & .006 & 1.676 & 1 & .195 & 1.008 \\
\hline Income & .126 & .050 & 6.381 & 1 & .012 & 1.135 \\
\hline Gender $(1=$ male, $0=$ female $)$ & -.656 & .200 & 10.773 & 1 & .001 & 1.927 \\
\hline $\operatorname{Race}(1=$ white, $0=$ nonwhite $)$ & .214 & .252 & .722 & 1 & .395 & .807 \\
\hline Block $1 \chi^{2}$ & 45.357 & & & 4 & .001 & \\
\hline Education & .042 & .091 & .211 & 1 & .646 & 1.043 \\
\hline Ideology $($ high = liberal) & .204 & .118 & 3.007 & 1 & .083 & 1.227 \\
\hline Party affiliation $($ high $=$ Democrat $)$ & .060 & .063 & .889 & 1 & .346 & 1.061 \\
\hline Block $2 \chi^{2}$ & 59.167 & & & 3 & .001 & \\
\hline Interpretation of the Bible ${ }^{\mathbf{b}}$ & .718 & .168 & 18.346 & 1 & .001 & 2.051 \\
\hline Religiosity $^{\mathrm{c}}$ & -.275 & .070 & 15.479 & 1 & .001 & .760 \\
\hline Attitude toward gay marriage ${ }^{d}$ & -.552 & .115 & 22.898 & 1 & .001 & .576 \\
\hline Block $3 \chi^{2}$ & 121.001 & & & 3 & .001 & \\
\hline Education by Ideology & .125 & .112 & 1.248 & 1 & .264 & 1.134 \\
\hline Income by Ideology & .052 & .111 & .216 & 1 & .642 & 1.053 \\
\hline Education by Religiosity & .317 & .124 & 6.493 & 1 & .011 & 1.373 \\
\hline Income by Religiosity & .023 & .117 & .040 & 1 & .842 & 1.024 \\
\hline Block $4 \chi^{2}$ & 11.569 & & & 4 & .021 & \\
\hline Tests & & & $x^{2}$ & $d f$ & $p$ & \\
\hline $\begin{array}{l}\text { Overall model evaluation: } \\
\text { Likelihood ratio test }\end{array}$ & & & 237.094 & 14 & .001 & \\
\hline Goodness-of-fit test & & & & & & \\
\hline Hosmer \& Lemeshow & & & 10.047 & 8 & .262 & \\
\hline Cox \& Snell $R^{2}$ & .301 & & & & & \\
\hline Nagelkerke $R^{2}$ & .403 & & & & & \\
\hline
\end{tabular}

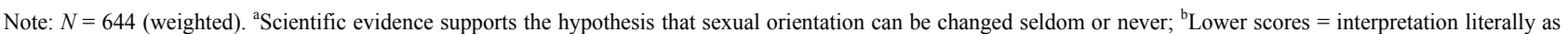
the word of God, higher scores $=$ less literal interpretation; ${ }^{c}$ Higher scores mean greater frequency of attending religious services; ${ }^{\mathrm{d}}$ Lower scores $=$ approval of gay marriage, higher scores $=$ disapproval.

thoritarianism, lower opinionation, greater ability to see both sides of an argument, and a positive interaction of income with ideology.

The overall picture that emerges from these tables is that, while there is some variation in results, it is not a matter of one variable such as education being more important than another, such as ideology. Certain variables work together to define publics that are characterized by higher education, tendencies toward liberalism and Democratic partisanship, and lower religiosity, and others that are characterized by higher religiosity, greater conservatism, and greater Republican partisanship. There are no surprises here, as other research has demonstrated. One can concentrate on the divisions between these groups, or one can look for ways in which communication can be framed by the opposing group's values, for example. Working to prevent global warming can be presented as patriotism to preserve natural resources and the American way of life (Feygina, Jost, $\&$ Goldsmith, 2010) and a religious value to provide steward- ship of natural resources.

\section{Conclusions}

People's belief-knowledge derives from a complex set of vantage points, depending upon family structure and interaction patterns, social and cultural networks and structure, psychological make-up and values, assumptions about the way the world works, and even genetic traits and neurological processing, to name a few. Carney, Jost, Gosling, \& Potter (2008, pp. 835-836) observed: "Political orientation appears to pervade almost every aspect of our public and private lives, possibly now more than in recent decades..." Scientists and others who believe in the scientific method have one way of testing knowledge in the hope of approaching truth, and some other social segments rely on other methods, such as religious faith. The multitude of differences makes it very easy for different groups to disrespect each other. In fact, the divisions sometimes 


\section{GAZIANO}

Table 2.

Logistic regression analysis of beliefs about evolution.

\begin{tabular}{|c|c|c|c|c|c|c|}
\hline $\begin{array}{l}\text { Some people think that humans and other living } \\
\text { form since the beginning of time. Which of the }\end{array}$ & $\begin{array}{l}\text { gs have evc } \\
\text { mes closest }\end{array}$ & $\begin{array}{l}\text { ime. O } \\
\text { w? [or } \\
\text { er time }\end{array}$ & $\begin{array}{l}\text { ink that hum } \\
\text { ternatives w }\end{array}$ & & $\begin{array}{l}\text { ings } h \\
d \text { in } p\end{array}$ & $\begin{array}{l}\text { isted in their present } \\
\text { form," } 1=\text { "evolved }\end{array}$ \\
\hline Predictors & $\beta$ & $S E \beta$ & Wald's $\chi^{2}$ & $d f$ & $p$ & $\operatorname{Exp}(\beta)$ (odds ratio) \\
\hline Constant & -3.502 & .654 & 28.718 & 1 & .001 & \\
\hline Age & -.014 & .006 & 5.501 & 1 & .019 & .987 \\
\hline Income & -.074 & .048 & 2.332 & 1 & .127 & .929 \\
\hline Gender $(1=$ male, $0=$ female $)$ & -.283 & .187 & 2.275 & 1 & .131 & 1.327 \\
\hline Race $(1=$ white, $0=$ nonwhite $)$ & .636 & .260 & 5.983 & 1 & .014 & .530 \\
\hline Block $1 \chi^{2}$ & 23.911 & & & 4 & .001 & \\
\hline Education & .431 & .094 & 20.846 & 1 & .001 & 1.539 \\
\hline Ideology $($ high $=$ liberal $)$ & .406 & .116 & 12.227 & 1 & .001 & 1.501 \\
\hline Party affiliation (high $=$ Democrat) & .134 & .061 & 4.850 & 1 & .028 & 1.144 \\
\hline Block $2 \chi^{2}$ & 113.222 & & & 3 & .001 & \\
\hline Interpretation of the Bible ${ }^{b}$ & .229 & .163 & 57.123 & 1 & .001 & 3.419 \\
\hline Religiosity $^{\mathrm{c}}$ & -.141 & .068 & 4.268 & 1 & .039 & .869 \\
\hline Teaching creationism with evolution in schools ${ }^{\mathrm{d}}$ & -.280 & .202 & 1.926 & 1 & .165 & .756 \\
\hline Block $3 \chi^{2}$ & 97.719 & & & 3 & .001 & \\
\hline Education by Ideology & -.254 & .117 & 4.689 & 1 & .030 & .775 \\
\hline Income by Ideology & .055 & .114 & .233 & 1 & .630 & 1.057 \\
\hline Education by Religiosity & -.398 & .130 & 9.366 & 1 & .002 & .672 \\
\hline Income by Religiosity & -.050 & .110 & .208 & 1 & .648 & .951 \\
\hline Block $4 \chi^{2}$ & 18.358 & & & 4 & .001 & \\
\hline Tests & & & $\chi^{2}$ & $d f$ & $p$ & \\
\hline Overall model evaluation: Likelihood ratio test & & & 253.210 & 14 & .001 & \\
\hline Goodness-of-fit test & & & & & & \\
\hline Hosmer \& Lemeshow & & & 12.341 & 8 & .137 & \\
\hline Cox \& Snell $R^{2}$ & .300 & & & & & \\
\hline Nagelkerke $R^{2}$ & .401 & & & & & \\
\hline
\end{tabular}

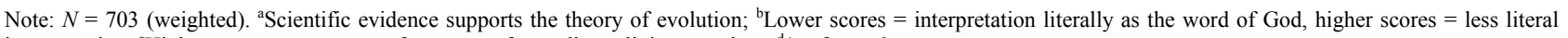
interpretation; ${ }^{c}$ Higher scores mean greater frequency of attending religious services; ${ }^{\mathrm{d}} 1=$ favor, $0=$ oppose.

are so stark that resolving the conflicts between them can be a daunting task. These groups seek to control knowledge definition and dissemination, and they differ in the ways they value various kinds of knowledge. In fact, they increasingly seek to control the political system rather than to work out differences (Abramowitz \& Saunders, 2005; Hindman, 2009; Hindman \& Yan, 2012; Shapiro \& Bloch-Elkon, 2008).

What are the long-term sociopolitical consequences of increasing acrimony between groups divided by ideology?
Americans need to be alarmed at the degree of polarization and aspects of the political system that allow it to be entrenched (Mann \& Ornstein, 2012; Nisbet \& Scheufele, 2012), while recognizing that differences between conservatives and liberals can bring balance to policy outcomes (Jost, 2006). Haidt and Graham (2007) stated (p. 110): "We in psychology, and in academe more generally, have a tendency to reject conservative concerns related to ingroup, authority, and purity as 'bad' on the grounds that they often conflict with the 'good' moralities 


\section{GAZIANO}

Table 3.

Logistic regression analysis of beliefs about evidence of global warming.

\begin{tabular}{|c|c|c|c|c|c|c|}
\hline \multicolumn{7}{|c|}{$\begin{array}{c}\text { From what you've read and heard, is there solid evidence that the average temperature on earth has been getting warmer over the past few decades, } \\
\text { or not? }(0=\text { "no," } 1=\text { "yes" })\end{array}$} \\
\hline Predictors & $\beta$ & $S E \beta$ & Wald's $\chi^{2}$ & $d f$ & $p$ & $\operatorname{Exp}(\beta)$ (odds ratio) \\
\hline Constant & -2.043 & .769 & 7.061 & 1 & .008 & \\
\hline Age & .015 & .007 & 4.928 & 1 & .026 & 1.015 \\
\hline Income & .082 & .054 & 2.288 & 1 & .130 & 1.086 \\
\hline Gender $(1=$ male, $0=$ female $)$ & -.496 & .219 & 5.131 & 1 & .023 & 1.648 \\
\hline Race $(1=$ white, $0=$ nonwhite $)$ & -.508 & .314 & 2.619 & 1 & .106 & 1.662 \\
\hline Block $1 \chi^{2}$ & 16.241 & & & 4 & .003 & \\
\hline Education & -.213 & .107 & 3.992 & 1 & .046 & .808 \\
\hline Ideology $($ high $=$ liberal $)$ & .101 & .133 & .580 & 1 & .446 & 1.106 \\
\hline Party affiliation (high $=$ Democrat $)$ & .194 & .072 & 7.261 & 1 & .007 & 1.215 \\
\hline Block $2 \chi^{2}$ & 28.057 & & & 3 & .001 & \\
\hline Interpretation of the Bible ${ }^{b}$ & .606 & .198 & 9.313 & 1 & .002 & 1.833 \\
\hline Religiosity $^{\mathrm{c}}$ & .142 & .085 & 2.795 & 1 & .095 & 1.153 \\
\hline Attitude toward stricter environmental laws ${ }^{\mathrm{d}}$ & 1.016 & .220 & 21.247 & 1 & .001 & 2.763 \\
\hline Block $3 \chi^{2}$ & 37.066 & & & 3 & .001 & \\
\hline Education by Ideology & .098 & .125 & .621 & 1 & .431 & 1.104 \\
\hline Income by Ideology & .155 & .129 & 1.444 & 1 & .229 & 1.167 \\
\hline Education by Religiosity & -.104 & .138 & .563 & 1 & .453 & .901 \\
\hline Income by Religiosity & -.140 & .125 & 1.260 & 1 & .262 & .869 \\
\hline Block $4 \chi^{2}$ & 8.448 & & & 4 & .076 & \\
\hline Tests & & & $\chi^{2}$ & $d f$ & $p$ & \\
\hline Overall model evaluation: Likelihood ratio test & & & 89.812 & 14 & .001 & \\
\hline \multicolumn{7}{|l|}{ Goodness-of-fit test } \\
\hline Hosmer \& Lemeshow & & & 5.980 & 8 & .649 & \\
\hline Cox \& Snell $R^{2}$ & .117 & & & & & \\
\hline Nagelkerke $R^{2}$ & .193 & & & & & \\
\hline
\end{tabular}

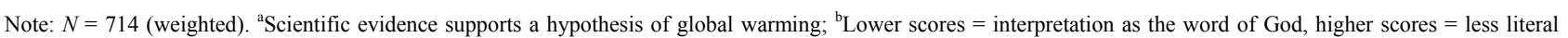
interpretation; ${ }^{\mathrm{C}}$ Higher scores mean greater frequency of attending religious services; ${ }^{\mathrm{d}} 1=$ Stricter laws and regulations are worth the cost, $0=$ cost too many jobs and hurt the economy.

of harm and fairness." They argued that unless liberals and conservatives can comprehend each other's differences in definitions, values, and moral motivations, they cannot work together to achieve their desired goals.

The Gaziano and Gaziano (1999, 2009) belief-knowledge gap framework treats ideology as a multidimensional concept and maintains that social and political groups differ in a multitude of ways that can make conservatives and liberals appear to be two different cultures ${ }^{15}$. The level of analysis is collective, rather than individual, a main tenet is that beliefs are knowledge, and the unit of analysis is belief-knowledge differences between ideological segments of social subsystems. Conserva-

\footnotetext{
${ }^{15}$ Another question is the effect on political moderates in times of threat, such as economic or national threat. Political moderates deserve more research since they are a large enough group to affect social policy; thus far, little research exists on them (Treier \& Hillygus, 2009).
}

tives and liberals tend to define belief-knowledge differently. This perspective allows for approaching ideology from a standpoint of understanding differences. Variables that figured prominently in knowledge gap studies may or may not be relevant to investigation on belief-knowledge. New investigations could examine some of these. Some examples of hypotheses and research questions for future research are shown as followed.

\section{Examples of Hypotheses}

1) The greater the level of perceived conflict in an issue, the greater the belief-knowledge gap between conservatives and liberals.

2) The greater the level of organized group activity on an issue, the greater the belief-knowledge gap between conservatives and liberals. 


\section{GAZIANO}

Table 4.

Logistic regression analysis of beliefs about the causes of global warming: human activity or natural patterns.

\begin{tabular}{|c|c|c|c|c|c|c|}
\hline Predictors & $\beta$ & $S E \beta$ & Wald's $\chi^{2}$ & $d f$ & $p$ & $\operatorname{Exp}(\beta)($ odds ratio $)$ \\
\hline Constant & -3.220 & .772 & 17.408 & 1 & .001 & \\
\hline Age & -.001 & .006 & .040 & 1 & .841 & .999 \\
\hline Income & -.043 & .052 & .673 & 1 & .412 & .958 \\
\hline Gender $(1=$ male, $0=$ female $)$ & -.287 & .212 & 1.833 & 1 & .176 & 1.333 \\
\hline Race $(1=$ white, $0=$ nonwhite $)$ & -.321 & .268 & 1.438 & 1 & .230 & 1.379 \\
\hline Block $1 \chi^{2}$ & 8.461 & & & 4 & .076 & \\
\hline Education & .277 & .096 & 8.336 & 1 & .004 & 1.319 \\
\hline Ideology $($ high $=$ liberal $)$ & .305 & .127 & 5.785 & 1 & .016 & 1.356 \\
\hline Party affiliation (high $=$ Democrat $)$ & .193 & .066 & 8.608 & 1 & .003 & 1.213 \\
\hline Block $2 \chi^{2}$ & 53.503 & & & 3 & .001 & \\
\hline Interpretation of the Bible ${ }^{\mathrm{b}}$ & .304 & .179 & 2.895 & 1 & .089 & 1.355 \\
\hline Religiosity $^{\mathrm{c}}$ & .082 & .083 & .965 & 1 & .326 & 1.085 \\
\hline Attitude toward stricter environmental laws ${ }^{\mathrm{d}}$ & 1.035 & .214 & 23.404 & 1 & .001 & 2.814 \\
\hline Block $3 \chi^{2}$ & 32.483 & & & 3 & .001 & \\
\hline Education by Ideology & .102 & .119 & .732 & 1 & .392 & 1.107 \\
\hline Income by Ideology & -.040 & .124 & .103 & 1 & .749 & .961 \\
\hline Education by Religiosity & -.096 & .128 & .564 & 1 & .453 & .908 \\
\hline Income by Religiosity & .346 & .127 & 7.482 & 1 & .006 & 1.414 \\
\hline Block $4 \chi^{2}$ & 11.214 & & & 4 & .024 & \\
\hline Tests & & & $\chi^{2}$ & $d f$ & $p$ & \\
\hline Overall model evaluation: Likelihood ratio test & & & 105.661 & 14 & .001 & \\
\hline \multicolumn{7}{|l|}{ Goodness-of-fit test } \\
\hline Hosmer \& Lemeshow & & & 8.413 & 8 & .394 & \\
\hline Cox \& Snell $R^{2}$ & .170 & & & & & \\
\hline Nagelkerke $R^{2}$ & .238 & & & & & \\
\hline
\end{tabular}

Note: $N=541$ (weighted). ${ }^{\text {a }}$ Scientific evidence supports a hypothesis of human causes; ${ }^{\mathrm{b}}$ Lower scores $=$ Interpret as the word of God, higher scores $=$ less literal interpretation; ${ }^{c}$ Higher scores mean greater frequency of attending religious services; ${ }^{\mathrm{d}} 1=$ Stricter laws and regulations are worth the cost, $0=$ cost too many jobs and hurt the economy.

3) The greater the insularity of specific media access and use, the greater the belief-knowledge gap between conservatives and liberals. Insularity means homogeneity of ideology among communication media.

4) The greater the insularity of membership in organized groups, the greater the belief-knowledge gap between conservatives and liberals.

5) The greater the insularity of interpersonal networks, the greater the belief-knowledge gap between conservatives and liberals.

6) Levels of education and income will interact with the magnitude of belief-knowledge gaps such that groups possessing lower education and higher income will have more conservative definitions of belief-knowledge.

7) Levels of religiosity and education will interact such that higher religiosity and lower education will be related to conservative definitions of belief-knowledge and lower religiosity and higher education will be related to liberal definitions of 


\section{GAZIANO}

Table 5.

Logistic regression analysis of beliefs about allowing gay men and lesbians to adopt children.

\begin{tabular}{|c|c|c|c|c|c|c|}
\hline \multicolumn{7}{|c|}{ Do you think gay or lesbian couples, in other words, homosexual couples, should be legally permitted to adopt children? (1 = "yes," 0 = "no") } \\
\hline Predictors & $\beta$ & $S E \beta$ & Wald's $\chi^{2}$ & $d f$ & $p$ & $\operatorname{Exp}(\beta)$ (odds ratio $)$ \\
\hline Constant & -3.030 & .649 & 21.802 & 1 & .001 & \\
\hline Age & -.025 & .004 & 41.715 & 1 & .001 & .975 \\
\hline Income & .003 & .012 & .079 & 1 & .779 & 1.003 \\
\hline Gender $(1=$ male, $0=$ female $)$ & -.646 & .136 & 22.555 & 1 & .001 & 1.908 \\
\hline Race $(1=$ white, $0=$ nonwhite $)$ & -.200 & .183 & 1.203 & 1 & .273 & 1.222 \\
\hline Block $1 \chi^{2}$ & 125.605 & & & 4 & .001 & \\
\hline Education & .116 & .033 & 12.212 & 1 & .001 & 1.123 \\
\hline Ideology $($ high $=$ liberal $)$ & .278 & .059 & 22.504 & 1 & .001 & 1.321 \\
\hline Party affiliation $($ high $=$ Democrat $)$ & .120 & .040 & 9.128 & 1 & .003 & 1.127 \\
\hline Block $2 \chi^{2}$ & 223.516 & & & 3 & .001 & \\
\hline Interpretation of the Bible $\mathrm{a}^{\mathrm{a}}$ & .779 & .114 & 46.930 & 1 & .001 & 2.179 \\
\hline Religiosity $^{\mathrm{b}}$ & -.204 & .046 & 19.701 & 1 & .001 & .816 \\
\hline Authoritarian child rearing values score & -.185 & .066 & 8.004 & 1 & .005 & .831 \\
\hline How many opinions $\mathrm{R}$ has & -.184 & .078 & 5.582 & 1 & .018 & .832 \\
\hline $\begin{array}{l}\text { How often } \mathrm{R} \text { can see two disagreeing parties as } \\
\text { both being right }\end{array}$ & .225 & .076 & 8.653 & 1 & .003 & 1.252 \\
\hline Block $3 \chi^{2}$ & 170.596 & & & 5 & .001 & \\
\hline Education by Ideology & .035 & .081 & .188 & 1 & .665 & 1.036 \\
\hline Income by Ideology & .157 & .072 & 4.791 & 1 & .029 & 1.170 \\
\hline Education by Religiosity & -.126 & .076 & 4.726 & 1 & .099 & .882 \\
\hline Income by Religiosity & -.042 & .080 & .278 & 1 & .598 & .959 \\
\hline Block $4 \chi^{2}$ & 11.779 & & & 4 & .019 & \\
\hline Tests & & & $\chi^{2}$ & $d f$ & $p$ & \\
\hline Overall model evaluation: Likelihood ratio test & & & 531.495 & 16 & .001 & \\
\hline Goodness-of-fit test & & & & & & \\
\hline Hosmer \& Lemeshow & & & 5.505 & 8 & .702 & \\
\hline Cox \& Snell $R^{2}$ & .305 & & & & & \\
\hline Nagelkerke $R^{2}$ & .407 & & & & & \\
\hline
\end{tabular}

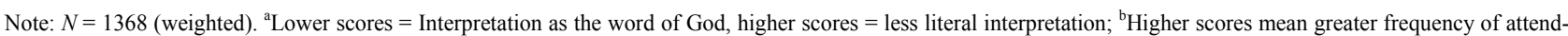
ing religious services.

belief-knowledge.

8) As polarization between conservatives and liberals increases, income inequality within the society will increase over time, as suggested by McCarty et al. (2006).

9) Since well-educated conservatives tend to have higher incomes than well-educated liberals, who make up a smaller proportion of the citizenry, income inequality will increase between the better-educated conservatives and the better-educated liberals.

\section{Examples of Research Questions}

1) Does size of collectivity, such as a community or a society, make a difference in the magnitude of belief-knowledge gaps? 
2) Does complexity (homogeneity or heterogeneity) of collectivity make a difference in the magnitude of belief-knowledge gaps?

3) Does level of issue impact on the collectivity affect magnitude of belief-knowledge gaps?

4) Does level of issue importance on the individual level influence magnitude of belief-knowledge gaps?

5) Does the number of economic and political power bases in the collectivity, such as a community or a society, influence the magnitude of belief-knowledge gaps? Pluralistic communities can handle more intensive conflict with their increased numbers of information outlets and power bases than can smaller, more homogeneous communities (Donohue et al., 1975; Tichenor, Donohue, \& Olien, 1980; Tichenor, Rodenkirchen, Olien, \& Donohue, 1973).

6) Does this hold for belief-knowledge gaps if the scope (local, state, regional, or national) of issues varies?

7) What about comparisons when the communication variable is information available in the social system, either generally, during community debates on issues, or in information campaigns, as compared with exposure or attention on the individual level? ${ }^{16}$

8) What about the character of information networks (interpersonal, organized group, media) and the amount and type of access to specific types of networks?

9) Under what conditions can belief-knowledge gaps be narrowed or closed?

10) What does it take for liberals and conservatives to change their focus from winning at any cost to working together to solve problems?

When ideological conflicts are viewed as tensions between cultures, it is possible to adopt a more anthropological assessment, as many would in addressing conflicts between racial, ethnic, or cultural groups in communities or within or between nations. Instead of demonizing the other culture, one can begin to frame solutions by accepting the other as valid, by trying to understand the differences, and by appealing to the other cultural groups' values, conceptual systems (Ecklund \& Scheitle, 2007; Lakoff, 1996), mores, and social life (Haidt \& Graham, 2007). Scientists with religious affiliations can help to bridge divisions between ideological groups when religiosity plays a role and can "productively contribute to dialogue about what distinguishes scientific and religious claims" (Ecklund \& Scheitle, 2007). An important question for future consideration is how the interests and beliefs of conservatives and liberals, as well as moderates, can be addressed to improve social and political system functioning instead of driving them further apart.

\section{Acknowledgements}

I thank Emanuel (Manny) Gaziano, information consultant and programmer at obimages.net, of Minneapolis, Minnesota, USA, for his comments on an earlier draft of this paper.

\section{REFERENCES}

Abramowitz, A., \& Saunders, K. (2005). Why can't we all just get along? The reality of a polarized America. The Forum 3(2): Article 1. http://www.bepress.com/forum/vol3/iss2/art1

\footnotetext{
$\overline{{ }^{16} \text { An example of a knowledge gap study that included both collective and }}$ individual level communication variables is that of Jerit, Barabas, and Bol$\operatorname{sen}(2006)$.
}

Alford, J. R., Funk, C. L., \& Hibbing, J. R. (2005). Are political orientations genetically transmitted? American Political Science Review, 99, 153-167. http://dx.doi.org/10.1038/nn1979

Amodio, D. M., Jost, J. T., Master, S. L., \& Yee, C. M. (2007). Neurocognitive correlates of liberalism and conservatism. Nature Neuroscience, 10, 1246-1247. doi.org/10.1038/nn1979

Barker, D. C., \& Tinnick, J. D., III. (2006). Competing visions of parental roles and ideological constraint. American Political Science Review, 100, 249-263. http://dx.doi.org/10.1017/S0003055406062149

Bartels, L. M. (2002). Beyond the running tally: Partisan bias in political perceptions. Political Behavior, 24, 117-149. http://dx.doi.org/10.1023/A:1021226224601

Blake, K. R., \& Culley, M. (2011). Polarized lenses: Party identification and Tennesseans' ratings of the state and national economies, 2004-2011. Meeting of the Midwest Association for Public Opinion Research, Chicago, IL.

Block, J., \& Block, J. H. (2006). Nursery school personality and political orientation two decades later. Journal of Research in Personality, 40, 734-749. http://dx.doi.org/10.1016/j.jrp.2005.09.005

Bowlby, J. (1969). Attachment and loss: Vol. 1. Attachment. New York: Basic Books.

Brossard, D., Scheufele, D. A., Kim, E., \& Lewenstein, B. V. (2009). Religiosity as a perceptual filter: Examining processes of opinion formation about nanotechnology. Public Understanding of Science, 18, 546-559. http://dx.doi.org/10.1177/0963662507087304

Burack, C. (2008). Sin, sex, and democracy: Antigay rhetoric and the Christian Right. Albany, NY: State University of New York Press.

Carney, D. R., Jost, J. T., Gosling, S. D., \& Potter, J. (2008). The secret lives of liberals and conservatives: Personality profiles, interaction styles, and the things they leave behind. Political Psychology, 29, 807-840. http://dx.doi.org/j.1467-9221.2008.00668.x

Crittenden, P. M., \& Ainsworth, M. D. S. (1989). Child maltreatment and attachment theory. In D. Cicchetti, \& V. Carlson (Eds.), Child maltreatment: Theory and research on the causes and consequences of child abuse and neglect (pp. 432-463). New York: Cambridge University Press.

Daves, R. P., White, H. A., \& Everett, S. E. (2011). The belief gap: More than just one issue. Meeting of the Midwest Association for Public Opinion Research, Chicago, IL.

Donohue, G. A., Tichenor, P. J., \& Olien, C. N. (1975). Mass media and the knowledge gap: A hypothesis reconsidered. Communication Research, 2, 3-23. http://dx.doi.org/10.1177/009365027500200101

Donohue, G. A., Tichenor, P. J., \& Olien, C. N. (1973). Mass media functions, knowledge and social control. Journalism Quarterly, 50, 652-659. http://dx.doi.org/10.1177/107769907305000404

Ecklund, E. H., \& Scheitle, C. P. (2007). Religion among academic scientists: Distinctions, disciplines, and demographics. Social Problems, 54, 289-307. http://dx.doi.org/10.1525/sp.2007.54.2.289

Evans, J. H., \& Evans, M. S. (2008). Religion and science: Beyond the epistemological conflict narrative. Annual Review of Sociology, 34, 87-105. http://dx.doi.org/10.1146/annurev.soc.34.040507.134702

Feldman, S., \& Stenner, K. (1997). Perceived threat and authoritarianism. Political Psychology, 18, 741-770. http://dx.doi.org/0162-895X.00077

Fernbach, P. M., Rogers, T., Fox, C. R., \& Sloman, S. A. (2013). Political extremism is supported by an illusion of understanding. Psychological Science, 24, 939-946. http://dx.doi.org/10.1177/0956797612464058

Feygina, I., Jost, J. T., \& Goldsmith, R. E. (2010). System justification, the denial of global warming, and the possibility of "system-sanctioned change". Personality and Social Psychology Bulletin, 36, 332-338. http://dx.doi.org/10.1177/0146167209351435

Gaines, B. J., Kuklinski, J. H., Quirk, P. J., Peyton, B., \& Verkuilen, J. (2007). Same facts, different interpretations: Partisan motivation and opinion on Iraq. Journal of Politics, 69, 957-974. http://dx.doi.org/j.1468-2508.2007.00601.x

Gauchat, G. (2008). A test of three theories of anti-science attitudes. Sociological Focus, 41, 337-357.

http://dx.doi.org/10.1080/00380237.2008.10571338

Gauchat, G. (2010). The politicization of science in the public sphere. 
Doctoral Dissertation.

http://digitalcommons.uconn.edu/dissertations/AAI3476645

Gauchat, G. (2012). Politicization of science in the public sphere: A study of public trust in the United States, 1974 to 2010. American Sociological Review, 77, 167-187. http://dx.doi.org/10.1177/0003122412438225

Gaziano, C. (1997). Forecast 2000: Widening knowledge gaps. Journalism \& Mass Communication Quarterly, 74, 237-264. http://dx.doi.org/10.1177/107769909707400202

Gaziano, C. (2013). Components of the belief gap: Ideology and education. Manuscript Submitted for Publication.

Gaziano, C., \& Gaziano, E. (2009). Theories and methods in knowledge gap research. In D. W. Stacks, \& M. Salwen (Eds.), An integrated approach to communication theory and research (2nd ed.) (pp. 122-136). New York: Taylor \& Francis.

Gaziano, E., \& Gaziano, C. (1999). Social control, social change, and the knowledge gap hypothesis. In D. Demers \& K. Viswanath (Eds.), Mass media, social control, and social change: A macrosocial perspective (pp. 117-136). Ames, IA: Iowa State University Press.

Gerber, A., Huber, G. A., Raso, C., \& Ha, S. (2009). Personality and political behavior. http://ssrn.com/abstract=1412829

Gillath, O., \& Hart, J. (2009). The effects of psychological security and insecurity on political attitudes and leadership preferences. European Journal of Social Psychology, 40, 122-134.

http://dx.doi.org/10.1002/ejsp.614

Gramsci, A. (2000). The Antonio Gramsci reader: Selected writings 1916-1935, D. Forgacs (Ed.). New York: New York University Press.

Haidt, J., \& Graham, J. (2007). When morality opposes justice: Conservatives have moral intuitions that liberals may not recognize. Social Justice Research, 20, 98-116.

http://dx.doi.org/10.1007/s11211-007-0034-z

Hindman, D. B. (2009). Mass media flow and differential distribution of politically disputed beliefs: The belief gap hypothesis. Journalism \& Mass Communication Quarterly, 86, 790-808. http://dx.doi.org/10.1177/107769900908600405

Hindman, D. B. (2012). Knowledge gaps, belief gaps, and public opinion about health care reform. Journalism \& Mass Communication Quarterly, 88, 585-605.

http://dx.doi.org/10.1177/1077699012456021

Hindman, D. B., \& Yan, C. (2012, August). The knowledge gap vs. the belief gap and abstinence-only sex education. Meeting of the Association for Education in Journalism and Mass Communication, Chicago, IL.

Ho, S. S., Brossard, D., \& Scheufele, D. A. (2008). Effects of value predispositions, mass media use, and knowledge on public attitudes toward embryonic stem cell research. International Journal of Public Opinion Research, 20, 171-192.

http://dx.doi.org/10.1093/ijpor/edn017

Hunter, J. D. (1992). Culture wars: The struggle to define America. New York: Basic Books.

Hwang, Y., \& Jeong, S.-H. (2009). Revisiting the knowledge gap hypothesis: A meta-analysis of thirty-five years of research. Journalism \& Mass Communication Quarterly, 86, 513-532. http://dx.doi.org/10.1177/107769900908600304

Inbar, Y., Pizarro, D. A., \& Bloom, P. (2009). Conservatives are more easily disgusted than liberals. Cognition and Emotion, 23, 714-725. http://dx.doi.org/10.1080/02699930802110007

Iyengar, S., \& Hahn, K. S. (2009). Red media, blue media: Evidence of ideological selectivity in media use. Journal of Communication, 59, 19-39. http://dx.doi.org/10.1111/j.1460-2466.2008.01402.x

Iyengar, S., Sood, G., \& Lelkes, Y. (2012). Affect, not ideology: A social identity perspective on polarization. Public Opinion Quarterly, 76, 405-431. http://dx.doi.org/10.1093/poq/nfs038

Jerit, J., Barabas, J., \& Bolsen, T. (2006). Citizens, knowledge, and the information environment. American Journal of Political Science, 50, 266-282. http://dx.doi.org/10.1111/j.1540-5907.2006.00183.x

Jost, J. T. (2006). The end of the end of ideology. American Psychologist, 61, 651-670. http://dx.doi.org/10.1037/0003-066X.61.7.651

Jost, J. T., Glaser, J., Kruglanski, A. W., \& Sulloway, F. J. (2003).
Political conservatism as motivated social cognition. Psychological Bulletin, 129, 339-375.

http://dx.doi.org/10.1037/0033-2909.129.3.339

Jost, J. T., Napier, J. L., Thorisdottir, H., Gosling, S. D., Palfai, T. P., \& Ostafin, B. (2007). Are needs to manage uncertainty and threat associated with political conservatism or ideological extremity? Personality and Social Psychology Bulletin, 33, 989-1007. http://dx.doi.org/10.1177/0146167207301028

Koleva, S. P., \& Rip, B. (2009). Attachment style and political ideology: A review of contradictory findings. Social Justice Research, 22, 241258. http://dx.doi.org/10.1007/s11211-009-0099-y

Kuklinski, J. H., Quirk, P. J., Jerit, J., Schwieder, D., \& Rich, R. F. (2000). Misinformation and the currency of democratic citizenship. Journal of Politics, 62, 790-816. http://dx.doi.org/10.1111/0022-3816.00033

Ladwig, P. J. (2010). Knowledge or belief? Religiosity and ideology shape knowledge of controversial science. Paper presented to the meeting of the Midwest Association for Public Opinion Research, Chicago, IL.

Lakoff, G. (2002). Moral politics: How liberals and conservatives think (2nd ed.). Chicago, IL: University of Chicago Press. http://dx.doi.org/10.7208/chicago/9780226471006.001.0001

Layman, G. C., Carsey, T. M., \& Horowitz, J. M. (2006). Party polarization in American politics. Annual Review of Political Science, 9, 83-110. http://dx.doi.org/10.1146/annurev.polisci.9.070204.105138

Levendusky, M. (2009). The partisan sort: How liberals became Democrats and conservatives became Republicans. Chicago, IL: University of Chicago Press. http://dx.doi.org/10.7208/chicago/9780226473673.001.0001

Maccoby, E. E., \& Martin, J. A. (1983). Socialization in the context of the family: Parent-child interaction. In P. H. Mussen (Ed.), Handbook of child psychology (pp. 1-101). New York: Wiley.

Main, M., \& Solomon, J. (1986). Discovery of a disorganized disoriented attachment pattern. In T. B. Brazelton \& M. W. Yogman (Eds.), Effective development in infancy (pp. 95-124). Norwood, NJ: Ablex.

Mann, T. E., \& Ornstein, N. J. (2012). It's even worse than it looks. New York: Basic Books.

McCarty, N., Poole, K., \& Rosenthal, H. (2006). Polarized America: The dance of ideology and unequal riches. Cambridge, MA: The MIT Press.

McCright, A. M., \& Dunlap, R. E. (2011). The politicization of climate change and polarization in the American public's views of global warming, 2001-2010. The Sociological Quarterly, 52, 155-194. http://dx.doi.org/10.1111/j.1533-8525.2011.01198.x

Mooney, C. (2005). The Republican war on science. New York: Basic Books.

Nisbet, M., \& Scheufele, D. (2012). The polarization paradox: Why hyperpartisanship strengthens conservatism and undermines liberalism. Breakthrough Journal, 3, 55-69. http://thebreakthrough.org/journal/issue-3/the-polarization-paradox/\#

Nyhan, B. (2010). Why the "death panel" myth wouldn't die: Misinformation in the health care reform debate. The Forum, 8, 1-24. http://dx.doi.org/10.2202/1540-8884.1354

Nyhan, B., \& Reifler, J. (2010). When corrections fail: The persistence of political misperceptions. Political Behavior, 32, 303-330. http://dx.doi.org/10.1007/s11109-010-9112-2

Shapiro, R. Y., \& Bloch-Elkon, Y. (2008). Do the facts speak for themselves? Partisan disagreement as a challenge to democratic competence. Critical Review, 20, 115-139. http://dx.doi.org/10.1080/08913810802316373

Smith, A. M. (2001). Why did Armey apologize? Hegemony, homophobia, and the Religious Right. In A. E. Ansell (Ed.), Unraveling the right: The new conservatism in American thought and politics (pp. 148-172). New York: Westview.

Sturgis, P., \& Allum, N. (2004). Science in society: Re-evaluating the deficit model of public attitudes. Public Understanding of Science, 13, 55-74. http://dx.doi.org/10.1177/0963662504042690

Thomson, I. T. (2010). Culture wars and enduring American dilemmas. Ann Arbor, MI: University of Michigan Press.

Thorisdottir, H., Jost, J. T., Liviatan, I., \& Shrout, P. E. (2007). Psy- 


\section{GAZIANO}

chological needs and values underlying left-right political orientation: Cross-national evidence from eastern and western Europe. Public Opinion Quarterly, 71, 175-203.

http://dx.doi.org/10.1093/poq/nfm008

Thornhill, R., \& Fincher, C. L. (2007). What is the relevance of attachment and life history to political values? Evolution and Human Behavior, 28, 215-222.

http://dx.doi.org/10.1016/j.evolhumbehav.2007.01.005

Tichenor, P. J., Donohue, G. A., \& Olien, C. N. (1970). Mass media flow and differential growth in knowledge. Public Opinion Quarterly, 34, 159-170. http://dx.doi.org/10.1086/267786

Tichenor, P. J., Donohue, G. A., \& Olien, C. N. (1973). Mass communication research: Evolution of a structural model. Journalism Quarterly, 50, 419-425. http://dx.doi.org/10.1177/107769907305000301

Tichenor, P. J., Donohue, G. A., \& Olien, C. N. (1980). Conflict and the knowledge gap. In P. J. Tichenor, G. A. Donohue, \& C. N. Olien, (Eds.), Community conflict and the press (pp. 175-203). Beverly Hills, CA: Sage.

Tichenor, P. J., Rodenkirchen, J. M., Olien, C. N., \& Donohue, G. A. (1973). Community issues, conflict, and public affairs knowledge. In
P. Clarke (Ed.), New models for mass communication research (pp. 45-79). Beverly Hills, CA: Sage.

Treier, S., \& Hillygus, D. S. (2009). The nature of political ideology in the contemporary electorate. Public Opinion Quarterly, 73, 679-703. http://dx.doi.org/10.1093/poq/nfp067

Viswanath, K., \& Finnegan Jr., J. R. (1996). The knowledge gap hypothesis: Twenty-five years later. In B. R. Burleson (Ed.), Communication yearbook 19 (pp. 187-227). Thousand Oaks, CA: Sage.

Weber, C., \& Federico, C. M. (2007). Interpersonal attachment and patterns of ideological belief. Political Psychology, 28, 389-416. http://dx.doi.org/10.1111/j.1467-9221.2007.00579.x

Weise, D. R., Pyszczynski, T., Cox, C. R., Arndt, J., Greenberg, J., Solomon, S., \& Kosloff, S. (2008). Interpersonal politics: The role of terror management and attachment processes in shaping political preferences. Psychological Science, 19, 448-455. http://dx.doi.org/10.1111/j.1467-9280.2008.02108.x

Yearley, S. (2005). Making sense of science: Understanding the social study of science. London: Sage.

Zimmerman, J. (2002). Whose America? Culture wars in the public schools. Boston: Harvard University Press. 